\title{
First Year Transition Through a Cultural Lens: Face Strategies of Vietnamese Students
}

\author{
Linda Nguyen \\ RMIT University, Vietnam \\ Andrea Chester \\ RMIT University, Australia \\ Anne Herbert \\ RMIT University, Australia \\ Alison Lugg \\ RMIT University, Australia
}

\begin{abstract}
While Vietnamese students continue to enrol in international branch university campuses in Vietnam, little is known about the Vietnamese first year transition into these institutions, especially from a cultural perspective. This article presents the findings of four case studies that explored the face strategies used by Vietnamese undergraduate business students in transition to an international branch campus based in Vietnam. The use of collectivist and individualist face strategies was examined in three phases: at commencement, mid-way and at the end of the first year of studies. The findings suggest that collectivist face strategies might not be employed as often as expected by Vietnamese first year students in this context even though they transition from a Confucian heritage culture. Understanding face strategies can help anticipate challenges of Vietnamese students studying in English-medium environments and inform culturally sensitive practices in teaching and learning.
\end{abstract}

Keywords: International students; Vietnam; first year transition; international branch campus; teaching and learning.

\section{Introduction}

Vietnamese students who want to experience an international environment and high standards of teaching and learning enrol in branch campuses of international (dominantly western, English-medium) universities in Vietnam. These international branch campuses offer at least some face-to-face teaching and access to an academic program in Vietnam that is accredited by the institution in another country (Lane, 2011). While the number of foreign-backed universities and international branch campuses has been increasing in Vietnam (Tran \& Marginson, 2019; Trines, 2017), little research has been published on student transition in these universities.

Transitions in the first year of university have been recognised as a period in which students' learning behaviour and cognition grow considerably (Harvey, Drew \& Smith, 2006). The first year transition influences the students' sense of belonging, institutional commitment and/or academic success and consequently persistence (Bowman, Jarratt, Jang \& Bono, 2018). Most literature on first year transition has focused on academic and social dimensions of students' experiences rather than cultural aspects, even though teaching and learning can be culturally constructed (Cheah, Diong \& Yap, 2018). Research on students from Confucian-heritage cultures (CHC) has concentrated on the students' experience studying overseas, particularly in Western countries (e.g., Huq, 2011; Le \& McKay, 2018; Maggs, 2018; Nguyen, 2013; Tran, 2011). Less has been written about 
Vietnamese students' first year transition to international branch campuses based in their home country, especially on the impact of culture on this transition.

This article will explore the transition of Vietnamese students at an international branch campus based in Vietnam, particularly the face strategies employed by these students in their first year and the influence of these strategies on learning. Understanding this cultural aspect of teaching and learning from the perspective of students can improve the efficiency of international education (Wang, Andre \& Greenwood, 2015) such as the application of Western-based pedagogy in the Vietnam context.

\section{First Year Transition of Vietnamese Students to an International Branch Campus}

Vietnamese students studying in an English-medium tertiary environment can face a number of challenges. Lack of confidence in understanding and speaking English can be an obstacle preventing students from participating in social and learning activities. In a four-year study of Vietnamese students studying English-medium programs at a Vietnamese university, students reported language issues, especially related to discipline concepts; they opted to speak their first language to each other even though English was the language of instruction (Phan, Tran \& Blackmore, 2018). In addition to language, adaptation to Western ways of teaching have also been described in the literature. Nguyen (2013) for example, studied the experience of four exchange Vietnamese students who studied in Australia and found "academic apprehension" common. These Vietnamese students needed to adapt to different learning approaches, increased student autonomy, different formats of assessments, and learn how to make the most of available resources.

\section{The Vietnamese Concept of Face and its Impact on Learning}

The Vietnamese concept of face (or "thể diện") implies a "socially approved image of a person and is associated with concepts such as honour, self-respect, pride and dignity" (Nguyen, 2015a, p. 148). Face relates to social expectations and how one is viewed in the eyes of others. Vietnam has been labelled a "face culture" where face and the fear of losing face are important cultural features (Nguyen, 2015b). In education this Vietnamese cultural feature is thought to be one of the key barriers preventing the introduction of interactive learning among Vietnamese students and contributing to students' unwillingness to participate in university classroom activities (Nguyen, 2015b).

The meaning of face is understood somewhat differently across cultures (Hwang \& Han, 2010; Pham, 2014). The Vietnamese concept of face is more likely to be concerned with positive face (the desire to be approved of) while the Western concept of face consists of two components: positive face and negative face (the desire to be free from imposition), as explained by the politeness theory of Brown and Levinson (1987). Other research indicates that collectivists are more concerned with positive face for inclusion and approval while individualists tend to pay more attention to maintaining negative face for freedom and autonomy (Nguyen-Phuong-Mai, Terlouw \& Pilot, 2014). Vietnam is typically considered a collectivist society (Hofstede Insights, n.d; Pham, 2018).

Individualist and collectivist cultures have different preferences regarding face strategies when saving face or when their face is threatened. Individualist cultures tend to use face enhancement, situational attribution and face-threatening style (NguyenPhuong-Mai et al., 2014). Face enhancement is a face strategy used to make oneself stand out from others (e.g. "I believe I can do it"). To save face, situational attribution is used to blame external factors such as other people or the situation (NguyenPhuong-Mai et al., 2014). Finally, face threatening strategies use confrontation and dominance towards others.

Collectivist cultures have been characterised as using internal attribution and face effacement strategies (Nguyen-Phuong-Mai et al., 2014). Internal attributions such as negative personality traits are used to accept face loss, while face effacement is used as a form of modesty (e.g. "I don't know much but I can learn") (Nguyen-Phuong-Mai et al., 2014; Ting-Toomey \& Kurogi, 1998).

This research explored the face strategies used by first year Vietnamese business students in their transition to an international branch campus based in Vietnam and how these face strategies changed over the course of their first year. 


\section{Method}

This study describes the experiences of four first-year students (two women and two men) enrolled full-time in undergraduate Business programs at an Australian university campus in Vietnam. Relevant demographic variables are presented in Table 1. Pseudonyms have been used to protect the anonymity of the participants.

\section{Table 1}

Demographic variables of the study participants

\begin{tabular}{|l|l|l|l|} 
Pseudonym & \multicolumn{1}{l}{ Sex } & Entry pathway & Vietnam Secondary School \\
\hline Nam & Male & Direct entry from school & Private secondary school \\
\hline Nga & Female & Direct entry from school & Public secondary school \\
\hline Van & Female & Direct entry from school & Public secondary school \\
\hline Vu & Male & English pathways program & Public secondary school \\
\hline
\end{tabular}

Upon enrolment new students were invited to join the study by email invitation. The participants described in this paper were part of a larger exploratory qualitative case study of eight Vietnamese students' first year transition into a foreign university branch campus. These four participants were chosen within the scope of this article as they represented students who transitioned to this English-medium university from a diversity of circumstances: direct entry (Nam, Van, Nga) and English programme $(\mathrm{Vu})$, private high school $(\mathrm{Nam})$ and public high schools (Van, Nga, Vu). They studied in three different undergraduate Business programs at the university and represented varied perspectives of first year transition.

While acknowledging limitations of the case study methodology as outlined by Yin (2009) (e.g., generalisability, mass of data, and lack of causation), the approach was chosen to enable us to focus on real life experiences as the first-year students were living them. The case study approach enabled us to examine in depth how the students experienced and interpreted their transition to university (Yin, 2009). Before commencement, the project was granted ethics approval by the university ethics committee (ethics approval number: CHEAN B 20625-02-17). None of the research team members were working in the School where the students were enrolled.

The first author conducted all semi-structured telephone interviews in Vietnamese language, each approximately 45 to 60 minutes in duration at three time points: before the start of first semester, mid-way through the first year and at the end of the first year. Interview questions focused on participants' expectations and experiences of academic success in their first year at university. All interviews were audio-recorded, transcribed and translated into English by the first author and two independent translators. By removing visual clues through telephone interviews, it was anticipated that the status of researcher and participants would, to some extent, be equalised. This method was intended to encourage the participants to open up about their experiences. However, there is a likelihood that the participants might have used face strategies in the interviews, particularly as the researcher was a lecturer at their university. Therefore, assurance of anonymity was provided to encourage participants to talk more easily about matters that they perceived as sensitive.

Transcripts were coded using NVivo software and analysed for key themes using the five-step process outlined by Braun and Clarke (2006). The first author undertook the work of familiarising herself with the data, reading and rereading the transcripts. Although not originally the focus of the interviews, the concept of face emerged from these readings and the first author generated initial codes around this concept. From here all four authors searched for and then reviewed themes related to the concept of face across the transcripts. Work was then undertaken to define and name these themes. Throughout the analysis process the research team worked closely to question and validate interpretations. 


\section{Findings}

The use of face strategies is summarised across the three phases of the participants' first year (see Table 2). The three phases of data collection occurred (1) before the first trimester, (2) after the second trimester (mid-way through the first year) and (3) at the end of the third trimester (upon completion of the first year).

Table 2

Face strategies used by each participant across each phase

\begin{tabular}{|c|c|c|c|c|c|c|c|c|c|c|c|c|c|}
\hline \multirow{3}{*}{\multicolumn{2}{|c|}{ Phase }} & \multicolumn{12}{|c|}{ Participant } \\
\hline & & \multicolumn{3}{|c|}{ Nam } & \multicolumn{3}{|c|}{$\mathrm{Nga}$} & \multicolumn{3}{|c|}{ Van } & \multicolumn{3}{|c|}{$\mathrm{Vu}$} \\
\hline & & 1 & 2 & 3 & 1 & 2 & 3 & 1 & 2 & 3 & 1 & 2 & 3 \\
\hline \multirow[t]{2}{*}{ Collectivist culture } & Internal attribution & $\mathrm{x}$ & & $\mathrm{x}$ & $\mathrm{x}$ & $\mathrm{x}$ & $\mathrm{x}$ & $\mathrm{x}$ & $\mathrm{x}$ & $\mathrm{x}$ & & $\mathrm{x}$ & $\mathrm{x}$ \\
\hline & Face effacement & & & & & & & & $\mathrm{x}$ & $\mathrm{x}$ & & $\mathrm{x}$ & \\
\hline \multirow{3}{*}{$\begin{array}{l}\text { Individualist } \\
\text { culture }\end{array}$} & Face enhancement & $\mathrm{x}$ & $\mathrm{x}$ & $\mathrm{x}$ & $\mathrm{x}$ & $\mathrm{x}$ & $\mathrm{x}$ & $\mathrm{x}$ & $\mathrm{x}$ & $\mathrm{x}$ & & $\mathrm{x}$ & $\mathrm{x}$ \\
\hline & Situational attribution & & $\mathrm{x}$ & $\mathrm{x}$ & $\mathrm{x}$ & $\mathrm{x}$ & $\mathrm{x}$ & $\mathrm{x}$ & $\mathrm{x}$ & $\mathrm{x}$ & & $\mathrm{x}$ & $\mathrm{x}$ \\
\hline & Face threatening & & $\mathrm{x}$ & $\mathrm{x}$ & & & $\mathrm{x}$ & & & & & & \\
\hline
\end{tabular}

\section{First Phase: Before University Commencement}

In the first phase, three participants (Nam, Nga, Van) showed evidence of the collectivist face strategy of internal attribution. For example, Nga acknowledged that her own study habits at high school were not an effective learning approach:

I was lazy at high school, so if I had homework, I often did it very close to the deadline, or often past deadlines one or two days ... My study habit at high school were not good. (Nga)

The other collectivist face strategy, face effacement, was not evident in this first phase.

Individualistic strategies were also evident. For example, face enhancement was used by students when reflecting on their high school experience. For instance, Nam thought that presentations in English might be difficult for high school graduates when they first started studying at English-medium university but it would not be a problem to him. He would be proactive in tackling any issue, either presentation or essay writing in English:

I think [studying at university] will be a bit hard to get used to for high school students because we have not practised much. But with me it is not a difficulty. I think I can overcome it and do well with presentations. As for essays, I think there will be difficulties but I will prepare in advance. (Nam)

Van used face enhancement to distinguish her learning attitude from other peers. She was confident that her consistently good performance in high school would create momentum for her studies at university:

Ever since high school, my study has been quite good, my grades were always high and almost in the top 10 of my school. So I don't put much thought into how to not fail courses ... I am not the kind who plays too much and forgets to study, so I think I only have to work hard. (Van)

Nga's face enhancement was illustrated in the way she talked about how she actively managed better than her high school peers in preparing for the IELTS test. She took pride in her self-motivation for study:

Most of my friends went to (IELTS) training classes, but I chose to self-study at home. Because I noticed that learning IELTS was fundamentally about getting used to that exam, and a teacher would teach us how to use skills, and those things, especially a lot of IELTS materials are available on the Internet. I was able to find out those things myself, saved money and personally when I self-studied like that and achieved something, I felt prouder, because I motivated myself to study. (Nga)

The individualistic situational attribution strategy, to account for outcomes as being the result of the situation or other people so not to accept face loss, was also evident in this first phase. For example, participants anticipated that lecturers' teaching 
styles would be responsible for any negative learning experiences. Before entering university, Nga predicted that her ability to understand lectures would depend on the lecturers:

Listening to lectures may depend on the lecturers. I don't know yet but depending on the lecturers it may be easy, the way they talk will be easier for me personally to listen to, and with some it will be more difficult for me to hear. (Nga)

The participants did not demonstrate evidence of face threatening strategies in this first phase.

\section{Second Phase: Mid-way Through First Year}

In the middle of their first year, the two collectivist strategies, internal attribution and face effacement, were observed. Regarding internal attribution, Van blamed herself for her lack of skills needed to complete assignments. She said, "When I first started my study here, I expected my grades to be higher but after two semesters, my grades are not what I expected. I think this is due to my skills."

Time management/procrastination was an internal attribution cited by both $\mathrm{Nga}$ and $\mathrm{Vu}$. Nga spoke more about procrastination than the other three participants. Having admitted that she used to do homework very close to the deadline in high school, she maintained that pattern of behaviour at university: "I am prone to procrastination. It's entirely because of me." She did make an effort in her second semester to change such behaviour but was not able to sustain it:

I feel semester one was not good so I tried harder in semester two, but I could only keep that energy up for the first few weeks...

it's an individual problem ... but really, I think it affects my life greatly. (Nga)

Nga confessed that she was "embarrassed" when she had to consult a lecturer for help after she skipped their class: "I'd feel embarrassed [to ask for help] because I was absent in his/her class. But if I go to class normally then I'm not hesitant."

Face effacement first appeared when students were mid-way through their first year, evident in the interviews with Van and Vu. Accepting face loss when dealing with new jargon, Vu kept repeating that he was just like other peers sharing the same problem:

I think I'm similar to other students because there is a lot of new terminology for me. For example, in the Accounting subject that I studied last semester, I encountered a lot of new definitions... I had to look words up in the dictionary. That's how I can understand the content. I think I'm just similar to others. (Vu)

After studying at the branch campus for half of their first year, these participants showed that they used individualist face strategies more often than collectivist ones. In this phase, all three individualist face strategies were evident. The participants used face enhancement to talk about how their advanced skills helped them perform well at university. Nam, for example, used face enhancement to emphasise his strengths in verbal presentation:

That is one of my skills and I think when I present, I can encourage interaction between students and lecturers and I think it's a good skill when you can talk in front of people and elaborate your ideas. That's a good opportunity to develop a personal skill so I quite enjoy it. (Nam)

Both Nam and Nga highlighted their superior role as a leader in group work. While Nam got trust from peers to be nominated as leader, Nga's perfectionism made her think that she should be the one to "carry the team":

I was the leader for all six courses that I studied. One time I nominated myself, other times people just chose me. Some friends already studied with me in other courses so they trusted me and let me be the leader ... I also established my own reputation. (Nam)

I was not happy with some individuals in the group. Like sometimes when we were doing the assignment, I was anxious and didn't trust the quality of their work. There were times that I had to carry the team. I mean ... they did the work but I still had to fix them; it was like redoing the whole thing. (Nga)

The participants also used situational attribution in most cases to blame the course structure and the lecturers' teaching style for a negative impact on their learning. Nam, Nga and Vu frustratedly described course structures as "illogical", "messy", "very general" or changing frequently. For instance, Nam said, "I didn't like the structure of the Accounting subject. It took me around five weeks just to get used to the messy and illogical structure, which confused all students." 
Nga blamed the course and the lecturer's teaching style for discouraging her from attending classes:

In semester 2, I felt that learning with him was not really helping me to understand so it affected my level of comprehension of the course and my interest in the course ... Because of the nature of the course was like that, plus lecturer, who can't communicate, it leads to me not wanting to go to that class anymore. (Nga)

Face threatening was used by only one participant in this second phase. Nam explained how he used this strategy with both his lecturer and his team members in group work. He would actively confront his lecturer about his results after comparing the rubric with his performance:

When I first got the grade, I looked at the lecturer's comment and then reviewed my assignment, then I compared that to the marking rubric and read a paper that got a higher grade to compare why it's better. Finally, I also met the lecturer to ask why I got such grade. It was an unforgettable lesson to me. (Nam)

In another example, he informed his teammates about his high standards and expectation to score well:

I'm quite demanding, so when I'm the leader, I would be more proactive so I think I would make a team complete by being the leader. When I work with my teammates, I always tell them that my standards are high. When somebody is that demanding, it's better for me to be the leader rather than a member. (Nam)

\section{Third Phase: The End of First Year}

At the end of the first year there was still evidence of collectivist strategies amongst participants. For example, they used internal attribution to save face particularly when reflecting on a poor performance in assessment. For example, Van claimed to be a "passive" student when comparing herself with peers in the same team of an assessment:

In the last semester, I joined in a group full of excellent students who were very proactive. It turned out to be I was the passive one and I did less work and gave fewer opinions than them. (Van)

Poor time management led Vu to submit an assessment late. He acknowledged the face loss, using internal attribution:

Last semester, I missed the deadlines for Accounting, and this semester I submitted my assignment for International Trade several minutes late because I left editing and writing references, and making the cover page and table of content until the last minute ... I think that's my fault for not being able to manage my time effectively. It's such a waste that I missed one deadline each semester. $(\mathrm{Vu})$

For Nam not referencing properly led to mark deduction in his assignment. He commented, "I think I did my assignments well but in terms of references, I didn't do it the right way so my marks got deducted significantly. The lecturer said that the sources I used were unreliable."

Face effacement was used by Van when talking about a group assignment. When given an assessment that required students to interview some company leaders, Van gave all the credit to the luck of having a member in the group with the right connections. She said:

In our group, we were very lucky because one of us had a father who knew a director of a company, so it was easy for us to interview him. However, if I was in another group that had no relationship with anyone being in the top position of a company like that, I would have had no idea what to do. (Van)

All three face strategies associated with individualistic cultures were present in the final phase. Situational attribution was used by Van and Vu to criticise their programs, citing the lecturer's poor preparation and lack of confidence as well as changes to course structure.

The teachers don't prepare their lectures well and they're not very confident about their lecture and can't communicate effectively. Sometimes when we ask them questions, they are not even sure about their answers. (Van)

The course structure changed a lot so it did affect my study... I'm not too happy with it. (Vu) 
Face enhancement remained a common face strategy of all four participants when they talked about their learning progress or achievement of good results. For example, Vu used face enhancement to highlight his improvement in research skills and thus became more confident in himself:

From semester one until now, I've acquired a lot of useful knowledge, and I think such knowledge is a great foundation for me so that I can study and do research by myself, such as I can read from online sources to get information about finance, etc. and I'm quite confident with doing my own online research. $(\mathrm{Vu})$

Finally, face threatening was used by both Nam and Nga in this third phase. When he encountered a member with poor attitude, Nam would warn his colleague that he would report the case to the lecturer in order to change his team member's behaviour:

Regarding the groupwork experience... one negative experience I had was when there's this member who's always late to deadlines. Actually, I didn't want to report that to the lecturer but we did warn him that we would do so. Subsequently, he did cooperate. (Nam)

Nga reported a face-threatening strategy when arguing with a team member during group work. After receiving the lecturer's answer which confirmed her point was right, she decided that it would be the direction for the team to proceed in:

I did spend time giving her feedback but she still didn't receive it well... There are times like... (laugh) we argued, I was pretty sure that I was right but I still respected her and emailed the lecturer to ask. The lecturer gave us an answer, and my point was correct so I told her that's the final answer from the lecturer so we should proceed accordingly (Nga)

\section{Discussion}

Although based in a collectivist society, the Vietnamese students in this study employed individualist face strategies more often than collectivist face strategies in their first year transition to a locally-based international branch campus. These students' preference and frequency of using individualist face strategies might have been informed by their perceptions and expectations of a Western learning environment compared to local high schools and/or universities. Both collectivist and individualist face strategies were used but the frequency of individualist face strategies increased over the course of the first year. Although they did initially express "academic apprehension" as Nguyen (2013) found, the students' assertiveness and autonomy as learners, grew gradually during their first-year transition to this English-medium environment.

The most commonly observed individualist face strategy, face enhancement, was used by the participants to point out their skills, learning approaches and traits that distinguished them from their high school peers. Participants anticipated these same characteristics would facilitate their transition to the English-medium environment of this international branch campus. Participants also used situational attribution to explain difficulties in learning due to external factors such as changes in the course structure, assignment design and lecturer's teaching style. The students anticipated that they would encounter certain academic challenges in this new learning environment for which their high school experience did not prepare them. The students' preference for clear instruction and structured learning suggested that they would not embrace the implementation of student-centred learning which often requires more autonomy and collaborative decision-making. Given a preference for more didactic learning and teaching approaches, the move to the university learning environment may be even more challenging for CHC students. This presents a challenge for their lecturers to build these students' skills in both independent and collaborative learning modalities.

Face threatening was the least common individualist face strategy, used by only two participants. One male participant used it in the last two phases to confront both his lecturer and a team member when he was unclear about the lecturer's feedback on his assignment and his team member's poor attitude. Another female student started using this strategy at the end of her first year to tell her team member to follow her direction to do the group assignment when that was supported by the lecturer. These examples are in contrast to the value of harmony, one of the core characteristics of Confucian heritage culture (Hằng, Meijer, Bulte \& Pilot, 2015; 2017); criticising a teacher may jeopardise the harmonious social order (Merriam \& Kim, 2008). It is important to note that generally collectivists care more about positive face, wanting to be included and approved (Vietnamese concept of face) whereas individualists focus on maintaining negative face for freedom and autonomy (Nguyen-Phuong-Mai et al., 2014). The fact that both of these participants used face threatening to confront others from the middle instead of at the beginning of their first year might hint that they gained more assertiveness and shifted towards the individualist spectrum in their first year transition to this English-medium university. Whether this move towards individualism would transfer beyond the university context is unknown and could warrant further research. 
Two collectivist face strategies, internal attribution and face effacement, were utilised to explain the students' shortcomings in their first year experience in the international branch campus, mostly in time management skills, referencing, jargon and group work challenges, which are not taught or frequently practiced in local high schools. Accepting face loss using internal attributions and face effacement shows that these students were aware of weaknesses in their preparation for learning in an English-medium environment and hoped to seek more sympathy and support with these issues. It emphasises the need for universities with international branch campuses to provide targeted English-language skill building for academic learning in the first year of university and, perhaps, beyond.

\section{Conclusion}

This research contributes to the body of knowledge of first year transition of Confucian heritage culture students into Englishmedium branch campuses through a cultural lens. This study suggests the transition to a Western culture learning context influenced how students perceived and presented themselves to others in their first year experiences.

The findings of this case study of Vietnamese students show that the students' employment of face strategies moved towards the spectrum of individualist rather than collectivist approaches during the first year of university. This contrasts the collectivist characteristic of a Confucian heritage culture like Vietnam. Most of the students' use of individualist face strategies increased from mid-way to the end of their first year, suggesting that they learned strategies for adapting to the dominant culture of the Western university environment. Therefore, more comprehensive understanding of face strategies can anticipate challenges of Vietnamese students studying in English-medium environments, Further research may provide detailed insights into struggles that students experience in these settings and inform culturally sensitive practices in course design and university teaching.

Further research into first year students' adaptations to different educational cultural environments might help inform international branch campuses of Western universities to provide targeted support for students' transition to the English language medium and Western cultural learning systems. Future research might also investigate the face strategies used by Vietnamese university lecturers working in international branch campuses, building on the research of Nguyen (2015b). This research could be taken further to examine longer-term impacts of this cultural transition in the education context for students as they progress through their university degrees and move into work, industry and wider social environments.

\section{References}

Bowman, N. A., Jarratt, L., Jang, N., \& Bono, T. J. (2018). The unfolding of student adjustment during the first semester of college. Research in Higher Education, 60(3), 1-20. https://doi.org/10.1007/s11162-018-9535-X

Braun, V., \& Clarke, V. (2006). Thematic analysis. In H. Cooper (Ed.), APA handbook of research methods in psychology: Vol. 2. Research Designs (pp.57-71). American Psychological Association. https://psycnet.apa.org/doi/10.1037/13620004

Brown, P., \& Levinson, S. C. (1987). Politeness: Some universals in language usage (Vol. 4): Cambridge University Press.

Cheah, P. K., Diong, F. W., \& Yap, Y. O. (2018). Peer assessment in higher education: Using Hofstede's cultural dimensions to identify perspectives of Malaysian Chinese students. Pertanika Journal of Social Sciences \& Humanities, 26(3), 14711489.

Hằng, N., Meijer, M., Bulte, A., \& Pilot, A. (2015). The implementation of a social constructivist approach in primary science education in Confucian heritage culture: The case of Vietnam. Cultural Studies of Science Education, 10(3), 665693. https://doi.org/10.1007/s11422-014-9634-8

Hằng, N., Meijer, M., Bulte, A., \& Pilot, A. (2017). Designing a primary science curriculum in a globalizing world: How do social constructivism and Vietnamese culture meet? Cultural Studies of Science Education, 12(3), 739-760. https://ui.adsabs.harvard.edu/link gateway/2017CSSE...12..739H/doi:10.1007/s11422-015-9696-2

Harvey, L., Drew, S., \& Smith, M. (2006). The first-year experience: A review of literature for the Higher Education Academy. https://www.qualityresearchinternational.com/Harvey\%20papers/Harvey\%20and\%20Drew\%202006.pdf

Hofstede Insights. (n.d.). Country comparison. https://www.hofstede-insights.com/product/compare-countries/

Huq, A. (2011, October 27-30). Supporting successful academic and social transition of first year students into higher education: a case study of entrepreneurship students at RMIT University. [Conference paper] The Third Asian Conference on Education Osaka, Japan.

Hwang, K.-K., \& Han, K.-H. (2010). Face and morality in Confucian society. In M. H. Bond (Ed.), The Oxford handbook of Chinese psychology. Oxford University Press. 
Lane, J. E. (2011). Global expansion of international branch campuses: Managerial and leadership challenges. New Directions for Higher Education, 2011(155), 5-17. https://doi.org/10.1002/he.440

Le, H., \& McKay, J. (2018). Chinese and Vietnamese international students in Australia. International Journal of Educational Management, 32(7), 1278-1292. https://doi.org/10.1108/IJEM-08-2016-0180

Maggs, J. C. (2018). One classroom, two cultures: The experiences of Chinese students in an American college. International Journal for Infonomics (IJI), 11(1).

Merriam, S. B., \& Kim, Y. S. (2008). Non-Western perspectives on learning and knowing. New Directions for Adult and Continuing Education, 119, 71-81.

Nguyen-Phuong-Mai, M., Terlouw, C., \& Pilot, A. (2014). Revisiting Facework with a new analysis instrument. Journal of Intercultural Communication (36). https://immi.se/intercultural/nr36/nguyen.html

Nguyen, H. P. C. (2013). Absorbing Australian culture through the exchange program at RMIT International University in Vietnam. Journal of International Education and Leadership, 3(1), 1-9.

Nguyen, T. Q. T. (2015a). Gender discrimination in the way the Vietnamese talk about face thê diên. Qualitative Research Journal, 15(2), 147-154. https://doi.org/10.1108/QRJ-12-2014-0066

Nguyen, T. Q. T. (2015b). The influence of traditional beliefs on Vietnamese college lecturers' perceptions of face. Journal of Education for Teaching, 41(2), 203-214. https://doi.org/10.1080/02607476.2015.1031542

Pham, H. T. (2018). Assuring quality in higher education in a Confucian collectivist culture: The Vietnamese experience. Journal of Contemporary Educational Research, 2(4), 10-19. https://doi.org/10.26689/jcer.v2i4.405

Pham, T. H. T. (2014). Implementing cross-culture pedagogies: Cooperative learning at Confucian heritage cultures (Vol. 25). Springer Singapore

Phan, H. L. T., Tran, L. T., \& Blackmore, J. (2018). Internationalization, student engagement, and global graduates: A comparative study of Vietnamese and Australian students' experience. Journal of Studies in International Education, 23(1), 171-189. https://doi.org/10.1177\%2F1028315318803717

Ting-Toomey, S., \& Kurogi, A. (1998). Facework competence in intercultural conflict: An updated face-negotiation theory. International Journal of Intercultural Relations, 22(2), 187-225. https://psycnet.apa.org/doi/10.1016/S01471767(98)00004-2

Tran, L. T. (2011). Committed, face-value, hybrid or mutual adaptation? The experiences of international students in Australian higher education. Educational Review, 63(1), 79-94. https://doi.org/10.1080/00131911.2010.510905

Tran, L. T., \& Marginson, S. (2019). From recipient to partner in international education. University World News https://www.universityworldnews.com/post.php?story=20190114124551804

Trines, S. (2017). Education in Vietnam. https://wenr.wes.org/2017/11/education-in-vietnam

Wang, C. C., Andre, K., \& Greenwood, K. M. (2015). Chinese students studying at Australian universities with specific reference to nursing students: A narrative literature review. Nurse Education Today, 35(4), 609-619. https://doi.org/10.1016/j.nedt.2014.12.005

Yin, R. K. a. (2009). Case study research: Design and methods (Fourth Edition. ed.). SAGE.

\section{Please cite this article as:}

Nguyen, L., Chester, A., Herbert, A., \& Lugg, A (2020). First year transition through a cultural lens: Face strategies of Vietnamese students. Student Success, 11(2), 82-90. https://doi.org/10.5204/ssj.1675

This article has been peer reviewed and accepted for publication in Student Success. Please see the Editorial Policies under the 'About' section of the Journal website for further information

Student Success: A journal exploring the experiences of students in tertiary education

Except where otherwise noted, content in this journal is licensed under a Creative Commons Attribution 4.0 International Licence. As an open access journal, articles are free to use with proper attribution. ISSN: 2205-0795 